Article

\title{
Ratio of Land Consumption Rate to Population Growth Rate-Analysis of Different Formulations Applied to Mainland Portugal
}

\author{
Rita Nicolau ${ }^{1, *}$, João David ${ }^{2, *}$, Mário Caetano ${ }^{1,2}$ (1) and José M. C. Pereira ${ }^{3}$ (]) \\ DGT-Direção Geral do Território, 1099-052 Lisboa, Portugal; mario.caetano@dgterritorio.pt \\ NOVA IMS-NOVA Information Management School, 1070-312 Lisboa, Portugal \\ 3 CEF/ISA - Centro de Estudos Florestais, Instituto Superior de Agronomia, Universidade de Lisboa, \\ 1349-017 Lisboa, Portugal; jmocpereira@gmail.com \\ * Correspondence: rnicolau@dgterritorio.pt (R.N.); jcdavid@novaims.unl.pt (J.D.)
}

Received: 30 August 2018; Accepted: 21 December 2018; Published: 27 December 2018

\begin{abstract}
This paper presents a methodological approach for the assessment of the indicator 11.3.1: "Ratio of Land Consumption Rate to Population Growth Rate" proposed by the United Nations (UN), discussing the definitions and assumptions that support the indicator quantification, and analysing the results provided by different formulations applied to mainland Portugal, at the municipality level. Due to specific limitations related to the actual formula proposed by the UN (LCRPGR) for the computation of the indicator, an alternative formulation derived from Land Use Efficiency (LUE) was explored. Considering that the land to which the indicator refers may be described by specific classes represented in Land Cover Land Use (LCLU) maps, in the estimation of the land consumption rate we tested two LCLU datasets: Corine Land Cover and COS-the Portuguese LCLU reference map. For the estimation of the population growth rate, prior allocation of inhabitants to the areas where people are most likely to reside was deemed necessary, using a dasymetric mapping technique based on LCLU information. The results obtained for 2007-2011 and 2011-2015 showed, in most municipalities, an increase in the urban area and a decrease in urban population, leading to negative values both in LCRPGR and LUE in most of the territory. Clearly, LUE performed better than LCRPGR in what urban development monitoring and urban area dynamics trends are concerned. Furthermore, LUE was much easier to interpret.
\end{abstract}

Keywords: Sustainable Development Goals; urban land take; urban sprawl; population growth; land cover land use

\section{Introduction}

During the last decades, throughout the world, the expansion of urban land surpassed the growth of urban populations [1-3]. The intense migratory flow of population to urban areas has led to an unplanned growth of cities, which usually expand their geographic boundaries to accommodate more inhabitants. Urban growth is thus becoming more expansive than compact [2]. To control the unplanned urban sprawl, more sustainable land use policies are required.

The land take assessment produced by the European Environment Agency [4] for 2006-2012 reports that "based on the average for the EU-28, 52\% of all areas that changed to artificial surfaces were arable land or permanent crops in 2006". This means that several land cover types change to impervious cover, which in turn compromises the provision of important services provided by soils, namely the storage and filtering of water, and the transformation of nutrients and contaminants [4] - a direct call for the phenomenon to be monitored at proper spatial and temporal scales. 
In the framework of the Sustainable Development Goals (SDG) established for 2030 by the United Nations (UN), the United Nations Human Settlements Programme (UN-Habitat) - the focal point for all urbanisation and human settlement matters within the UN system - proposed the adoption of an indicator for urban development monitoring, named "ratio of Land Consumption Rate to Population Growth Rate". This indicator is also known as 11.3.1, because it is associated with the SDG 11"Make cities inclusive, safe, resilient and sustainable" — and more specifically with the target 11.3 that envisages to "enhance inclusive and sustainable urbanization and capacity for participatory, integrated and sustainable human settlement planning and management in all countries" by 2030 [1].

The indicator 11.3.1 aims at monitoring and measuring urban development by comparing the urban expansion rate with the population growth rate on similar temporal and spatial scales. Quantifying this indicator is essential to understand the speed of land take compared to the population growth, to recognise historical land consumption traditions and to guide decision-makers on urban growth planning and on the protection of environmental, social, and economic resources.

The estimation of the indicator 11.3.1 requires the evaluation of the surface occupied by urban areas and its inhabitants, at different temporal instants. In addition, its assessment demands the clarification of concepts appertaining to the land type/ inhabitants targeted by the land consumption/ population growth rate. Since the indicator is intended to monitor urban development, it is assumed that it refers to urban land consumption, meaning the newly developed (urbanised) urban land. However, a clear definition of urban land is still missing, and this definition is definitely required for the quantification of the surface occupied by urban areas. In order to standardise the definition and unit of measurement constituting urban areas, the UN-Habitat proposes to measure "the built-up area of the urban agglomeration" [1], which includes the city centre and its suburbs, forming a continuous urban settlement. Nevertheless, this standardised definition may have different geographic boundaries when referring to different scales, such as the city proper, the metropolitan area, or the urban agglomeration. As for the inhabitants targeted by the indicator, since most of the population lives in urban areas, it is often assumed that the residents in urban areas may be represented by the residents in administrative units containing such areas. This simplification avoids the need for a method to link the population data to the spatial extent of urban areas.

The indicators established under the 2030 SDG were classified into three tiers, based on their level of methodological development and the availability of data for their development at the global level. The indicator 11.3.1 has been classified as a tier II indicator, because it is conceptually clear and has an internationally established methodology for its calculation, although the data for its establishment are not regularly produced by countries. Nevertheless, the authors consider that the mathematical expression proposed by the UN-Habitat to calculate the indicator 11.3.1 (LCRPGR) [1] is inadequate because it can lead to indeterminate values. The discussion on the methodologies and the datasets available for the assessment of the indicator 11.3.1 is recent and has been confined to working groups collaborating with the UN for this purpose. Due to this fact, research describing its estimation at the country level is still scarce in the literature. However, the authors had access to some reports on the development experiences of the indicator, which are briefly described below.

In a work developed by a team at the Joint Research Centre [5], the ratio of land consumption rate to population growth rate was estimated at a global level for the period 1990-2015, using the expression proposed by the UN-Habitat. The base information used in this assessment includes the spatial distribution of built-up areas, settlement typologies, and population, obtained from the Global Human Settlement Layer (GHSL) [6,7]. Reporting to circa 10,000 urban areas identified for the globe, the LCRPGR estimate (0.72) obtained for the 1990-2015 period reflects an urban development in which the rate of population growth was higher than the land consumption rate.

The practices adopted to evaluate the indicator 11.3.1 have varied in different countries. In the UK, the Office for National Statistics used the coverage of surfaces identified as man-made to estimate land consumption rate and mid-year population estimates to calculate population growth rate for the period 2013-2016 [8]. The indicator 11.3.1 was assessed using the formula proposed by the UN-Habitat, for 
spatial units known as Lower layer Super Output Area (LSOA) in England, Scotland, and Wales. It is mentioned that the formula could not be applied to the spatial units where the population remained stable. Probably due to this fact, the results are not reported as LCRPGR estimates. Between 2013 and 2016, the population in Wales grew by $1.9 \%$ and the land consumption rate by $1.4 \%$. The highest LCRPGR estimate was registered in Scotland, where the population grew by $1.4 \%$ and the land consumption by $6.1 \%$. In England, the land consumption also grew faster than the population, with the land consumption growing by $4.4 \%$ and the population by $2.3 \%$.

In France, the indicator 11.3.1 is estimated for metropolitan areas using data on their artificial areas and on metropolitan population [9]. The results obtained for the period 2006-2015 indicate that the land consumption in metropolitan areas increased on average by $1.4 \%$ per year, while the metropolitan population grew by $0.5 \%$ per year.

In Italy, the indicator 11.3.1 is assessed through the ratio of high-density built-up areas to the population (square metres per inhabitant) [10]. Between 2001 and 2011, the value of this indicator increased from $349.1 \mathrm{~m}^{2} /$ inhabitant to $364 \mathrm{~m}^{2} /$ inhabitant.

In Colombia, the National Administrative Department of Statistics developed a pilot project to estimate the ratio of land consumption rate to population growth rate in the Barranquilla metropolitan area for the periods 2005-2010 and 2010-2015 [11]. The base data used in this study included Landsat images and population projected data. The indicator was assessed using a different formulation than that proposed by the UN-Habitat.

The UN-Habitat Workshop on the indicator 11.3.1 given by Dennis Mwaniki in 2018 [12], comprised, among other subjects, the presentation of several data sources available for the computation of urban land consumption and population growth, and elucidation of the steps required for the calculation of the indicator. The workshop also included a case-study applied to Ho Chi Minh City, Vietnam, which illustrated the computation of two versions of the indicator that reflect the external and internal growth of the city. During the workshop, it was recognised that the current method proposed to assess the indicator 11.3.1 has limitations and that proposals for its upgrade are still under discussion. In what concerns the inhabitants targeted by the indicator, it was highlighted that the estimation of the number of urban inhabitants usually requires spatial disaggregation of the population data.

Taking into account the implementation experiences described above, as well as the recognition that the formulation of the indicator presents weaknesses, the authors believe that there are still several aspects requiring examination to enable solid comparisons between countries. These include an agreement on (i) the concepts and assumptions that support the quantification of land consumption and population growth in urban areas, and (ii) the formulas and methods that can be applied for its assessment.

The main goal of this study is to propose a methodological approach for the assessment of the indicator 11.3.1 and to discuss the concepts that support its quantification. For this purpose, this paper shows how specific datasets can be used to produce proxies of the variables of interest and discusses the assumptions to be made for their use. The test of two mathematical expressions in the indicator 11.3.1 estimation enabled the assessment of their suitability for monitoring the phenomenon of interest. With this aim, the indicator was estimated with the formula currently proposed by the UN-Habitat (LCRPGR) [1] and with an alternative formulation based on Land Use Efficiency (LUE) [13]. Both were applied to Mainland Portugal, at the municipality level.

Given the scarcity of published studies on the evaluation of the indicator 11.3.1 at the country level, the authors believe that this work may be useful not only to other countries but also to the working groups involved in the discussion of 11.3.1.

The production of the indicator 11.3.1 for Portugal required specific articulation between Statistics Portugal and the Directorate-General for Territory (DGT, the National Mapping and Cadastre Agency). Both institutions participate in the Work Group on Data Integration, subgroup 2 of the UN-GGIM: Europe. This work was developed in the framework of the technical cooperation established for the exploration of land cover/ land use datasets in the assessment of the indicator. 


\section{Materials and Methods}

As mentioned in Section 1, the indicator 11.3.1 was assessed at the municipality level for Mainland Portugal using two mathematical expressions: the formula currently proposed by the UN-Habitat [1] and a Land Use Efficiency (LUE) adapted formula proposed by Corbane et al. in 2017 [13].

The formula currently proposed by the UN-Habitat (LCRPGR) measures the ratio between two rates:

$$
\begin{aligned}
& \text { LCRPGR }=\left(\frac{\text { Land Consumption Rate }}{\text { Population Growth Rate }}\right) \\
& \text { Land Consumption Rate }=\frac{\ln \left(\mathrm{Urb}_{\mathrm{t}+\mathrm{n}} / \mathrm{Urb}_{\mathrm{t}}\right)}{\mathrm{n}} \\
& \text { Population Growth Rate }=\frac{\ln \left(\mathrm{Pop}_{\mathrm{t}+\mathrm{n}} / \mathrm{Pop}_{\mathrm{t}}\right)}{\mathrm{n}}
\end{aligned}
$$

where

ln = Natural logarithm

$\mathrm{Urb}_{\mathrm{t}+\mathrm{n}}=$ Surface occupied by urban areas at the final year $(\mathrm{t}+\mathrm{n})$

$\mathrm{Urb}_{\mathrm{t}}=$ Surface occupied by urban areas at the initial year $(\mathrm{t})$

$\operatorname{Pop}_{\mathrm{t}+\mathrm{n}}=$ Population living in urban areas at the final year $(\mathrm{t}+\mathrm{n})$

Pop $_{\mathrm{t}}=$ Population living in urban areas at the initial year $(\mathrm{t})$

$\mathrm{n}=$ Number of years between the two time intervals.

The LUE formula adapted by Corbane et al. measures the change rate of the built-up area per capita $\left(\operatorname{Idx} x_{t}\right)$

$$
\operatorname{Idx} x_{t}=\frac{Y_{t}-Y_{t+n}}{Y_{t}}
$$

where

$$
\begin{aligned}
Y_{t} & =\frac{B U_{t}}{\operatorname{Pop}_{t}} \\
Y_{t+n} & =\frac{B U_{t+n}}{\operatorname{Pop}_{t+n}}
\end{aligned}
$$

$\mathrm{BU}_{\mathrm{t}}=$ Surface occupied by built-up at the initial year $(\mathrm{t})$

Pop $_{\mathrm{t}}=$ Total population within the built-up area at the initial year $(\mathrm{t})$

$\mathrm{BU}_{\mathrm{t}+\mathrm{n}}=$ Surface occupied by built-up at the final year $(\mathrm{t}+\mathrm{n})$

$\operatorname{Pop}_{\mathrm{t}+\mathrm{n}}=$ Total population within the built-up area at the final year $(\mathrm{t}+\mathrm{n})$

In order to ensure the comparability of the results at different time intervals, it is recommended to normalise the values of $I d x_{t}$ to obtain a 10-year average change. This is achieved by multiplying the indicator by 10 , divided by the number of years between the two observations (n).

$$
\operatorname{Idx}_{\mathrm{t} 10}=\frac{Y_{t}-Y_{t+n}}{Y_{t}} \times \frac{10}{n}
$$

The calculation of $\operatorname{Idx} x_{t 10}$ (Equation (7)), as an alternative to LCRPGR (Equation (1)), implies the adoption of similar assumptions regarding the type of urban areas covered by both indicators. Therefore, it was assumed that the surface occupied by built-up in Equation (7) also includes the open urban space, and is consequently equivalent to the surface occupied by urban areas used in Equation (1).

Depending on data availability, the assessment of the indicator 11.3.1 may be undertaken using different approaches.

The estimation of the surface occupied by urban areas, which is required for quantifying urban land consumption, has been carried out using different data sources, namely satellite 
imagery [11,14-16], Land Cover Land Use (LCLU) maps and surveys [17-19] or cadastral data [20,21]. The accuracy associated with the estimates depends on the information provided by each data source.

Remote sensing and classification techniques, network density analysis, fractal analysis, and clustering techniques are described by Nicolau et al. [22] as the most common approaches used for the identification of urban areas. The location of urban areas may also be estimated through suitability models [23], which evaluate how well the land cover fits a specific urban land use practice.

Many approaches aiming at the delineation of urban areas are based on LCLU maps, namely by using land cover classes considered contributory to the urban tissue and function. Such is the case of the Urban Morphological Zones (UMZ) [24,25] that can also be regarded as urban areas. The UMZ units were used as urban areas proxies in the assessment of urban sprawl in Europe developed by the European Environment Agency [26] for 1990-2000, as well as in other studies applied to urban areas [22,27,28].

The Global Human Settlement Layer (GHSL) produced by the Joint Research Centre (JRC) of the European Commission $[5-7,13]$ is a recent example of information derived from satellite imagery that provides free data on human settlements (GHS-BU) and population (GHS-POP) on a global scale. The GHSL uses various data sources including global, multi-temporal archives of fine-scale satellite imagery, census data, and volunteered geographic information [7]. The global layer on built-up surfaces (GHS-BU) was produced from Landsat image collections for four different periods: 1975, 1990, 2000 and 2014 [6,7]. Each consists of a gridded layer available for three resolutions: $38 \mathrm{~m}, 250 \mathrm{~m}$ and $1 \mathrm{Km}$. The GHS-POP provides information on resident population distribution and is available at two resolutions (250 $\mathrm{m}$ and $1 \mathrm{Km}$ ) for the following years: 1975, 1990, 2000, and 2015 [7]. The information provided by the GHSL layers enables to track at a global level the population growth in human settlements, as well as the urban extent growth.

Assuming that the population of interest for the indicator 11.3.1 calculation includes only residents in urban areas, its assessment may be accomplished through statistical modelling or through the spatial disaggregation of population data associated with administrative or census units [29]. Both approaches are supported by significant covariates, such as land cover data.

The spatial disaggregation of population data is usually performed by dasymetric mapping [30], a technique that uses ancillary information (covariates) to distribute data from source zones to target zones covering the same spatial domain. The dasymetric mapping technique has been widely used to produce raster datasets depicting the population distribution (also known as population density grids) [17,31-33]. The production of population density grids is mostly supported by LCLU data. In the framework of GHSL, this technique was applied in the disaggregation of residential population estimates from census or administrative units to grid cells, using as ancillary data the built-up areas mapped in the GHS-BU layers [32]. This technique was also applied in the creation of the European population distribution map $[17,31,33]$, using Corine Land Cover (CLC) as the main covariate.

The assessment of urban residents in areas identified through land cover data requires the establishment of a link between the population data and the land cover spatial units. This is not an easy task, since the population data is commonly associated with administrative or census units-which present very different boundaries from those defined in the land cover spatial units. Fortunately, the population density grids may help to establish such a link, whenever its spatial resolution is adequate. However, available datasets at the European level have resolutions varying between $100 \mathrm{~m}$ and $1 \mathrm{Km}[17,31-33]$, which are considered too coarse for estimating the number of inhabitants in Portuguese urban areas.

The methodological approach proposed in this study to assess the indicator 11.3.1 comprises two stages. The first includes the delineation of urban areas using land cover classes contributing to the urban tissue and function, and the evaluation of their surface at each temporal instant. The second includes the allocation of inhabitants to the areas where people are most likely to reside and the subsequent estimation of urban inhabitants at each temporal instant. 


\subsection{Data Sources Used in the Production of LCRPGR and LUE Indicators}

The base information used in the indicator 11.3.1 calculation includes residential population counts or estimates, for the municipal level, and land cover data extracted from the available maps: COS, the Portuguese LCLU reference map, and CLC, the European LCLU map. The annual population data, produced by Statistics Portugal, were linked to vector maps representing the boundaries of municipalities in the equivalent year.

COS (also known in Portugal as "Carta de Ocupação e uso do Solo") is a vector map produced by the DGT (Directorate-General for Territory) that has a Minimum Mapping Unit (MMU) of 1 ha. COS covers Mainland Portugal and is available for several years since 1995. CLC is also a vector map produced by the EEA (European Environment Agency), which presents an MMU of 25 ha. CLC is available for several years since 1990. These two maps share a common nomenclature with 43 classes organised in a three-tier hierarchical structure (Table A1 of Appendix A).

In this study, the land cover classes extracted from COS and CLC were used to delineate urban areas and served as ancillary data to estimate the residents in those areas.

Since COS and CLC are available for some dates that differ only one year from census dates, some assumptions anent to these datasets were made to avoid the use of inter-census population estimates in the assessment of the population living in urban areas per municipality. To allow a temporal match between census population and LCLU data, it was admitted that the land cover did not change significantly during a year, being therefore representative of the land cover at the closest census year. As a result, the LCLU data used in the population estimation for the years 2001 and 2011 (census years) correspond in fact to 2010 (if COS was used) and to 2000 and 2012 (if CLC was used).

The second stage of the methodology comprised the creation of population grid maps for 2001, 2006, 2007, 2011 and 2015 using annual resident population data per municipality, produced by Statistics Portugal. The population data used to produce the 2001 and 2011 maps were census data, whereas in the production of the 2006, 2007, and 2015 maps inter-census estimates were used.

In the production of the population grid maps for 2001, 2006, and 2011 a spatial resolution of $100 \mathrm{~m}$ was adopted, since CLC (for 2000, 2006, and 2012) was used as ancillary information.

In the production of the population grid maps for 2007, 2011, and 2015 a spatial resolution of $25 \mathrm{~m}$ was adopted, since COS (for 2007, 2010, and 2015) was used as ancillary information.

Table 1 identifies the main datasets used to produce LCRPGR and LUE indicators and the time-periods to which they relate.

Table 1. Main datasets used to produce LCRPGR and LUE indicators.

\begin{tabular}{|c|c|c|}
\hline Indicator Abbreviation & Indicator Time-Period & Datasets \\
\hline LUE_COS07_11 & 2007-2011 & $\begin{array}{l}\text { COS } 2007 \text { + Population estimates per municipality in } \\
2007 \text {; COS } 2010 \text { + Population per municipality in } 2011 \text {. }\end{array}$ \\
\hline LUE_COS11_15 & 2011-2015 & $\begin{array}{l}\text { COS } 2010 \text { + Population per municipality in 2011; COS } \\
2015 \text { + Population estimates per municipality in } 2015 .\end{array}$ \\
\hline LUE_CLC01_06 & 2001-2006 & $\begin{array}{l}\text { CLC } 2000 \text { + Population per municipality in 2001; CLC } \\
2006 \text { + Population estimates per municipality in } 2006 .\end{array}$ \\
\hline LUE_CLC06_11 & 2006-2011 & $\begin{array}{l}\text { CLC } 2006 \text { + Population estimates per municipality in } \\
\text { 2006; CLC } 2012 \text { + Population per municipality in } 2011 \text {. }\end{array}$ \\
\hline LCRPGR_COS07_11 & $2007-2011$ & $\begin{array}{l}\text { COS } 2007 \text { + Population estimates per municipality in } \\
2007 \text {; COS } 2010 \text { + Population per municipality in } 2011 \text {. }\end{array}$ \\
\hline LCRPGR_COS11-_15 & 2011-2015 & $\begin{array}{l}\text { COS } 2010 \text { + Population per municipality in 2011; COS } \\
2015 \text { + Population estimates per municipality in } 2015 \text {. }\end{array}$ \\
\hline LCRPGR_CLC01_06 & 2001-2006 & $\begin{array}{l}\text { CLC } 2000 \text { + Population per municipality in 2001; CLC } \\
2006 \text { + Population estimates per municipality in } 2006 .\end{array}$ \\
\hline LCRPGR_CLC06_11 & 2006-2011 & $\begin{array}{l}\text { CLC } 2006 \text { + Population estimates per municipality in } \\
\text { 2006; CLC } 2012 \text { + Population per municipality in } 2011 .\end{array}$ \\
\hline
\end{tabular}


It should be noted that the temporal disparity of the data sources used does not enable the comparison of estimates of the same indicator obtained through COS and CLC. The comparison of results produced by COS and by CLC is only feasible for the estimates produced for 2011, referring to the surface occupied by urban areas and the population living in these areas.

\subsection{Estimation of the Surface Occupied by Urban Areas in Each Year}

Given that our study is aimed at estimating the indicator 11.3.1 for the national and the municipal level, the spatial unit chosen to represent urban areas corresponds to the urban agglomeration (described by the UN-Habitat in 2009 [34] as "the built-up or densely populated area containing the city proper; suburbs, and continuously settled commuter areas" whose delimitation refers to "the total area occupied by the built-up area and its urbanized open space").

Considering that the area occupied by urban agglomerations may be roughly quantified by land cover classes portrayed in COS or in CLC, it was acknowledged that the Artificial areas (1) is the level 1 class that best represents the urban agglomerations. However, several Construction sites (133), which are contained by the Artificial areas class, may change to land cover classes distinct from Artificial areas after the construction phase. This land cover change may lead to reductions of the surface occupied by Artificial areas in relatively short periods. Due to this fact, it was assumed that the surface occupied by Artificial areas (1) excluding Construction sites (311) is a more reliable estimate of the area occupied by urban agglomerations in each year.

The area of each municipality occupied by urban agglomerations was computed through spatial analysis developed in a Geographical Information System (GIS). To ensure the comparability of this indicator at different moments, the measurement of the surface occupied by Artificial areas (1) excluding Construction sites (311) at different years was carried out using the same administrative limits, which correspond to the municipalities boundaries in 2013.

Figure 1 explains the methodology adopted for the evaluation of the surface occupied by urban agglomerations and correspondent population, per municipality. Steps A and B illustrate the assessment of the area occupied by urban agglomerations in each municipality.

\subsection{Estimation of the Population Living in Urban Areas in Each Year}

The estimation of the population living in urban agglomerations at each moment was performed in two steps. The first step (F) comprised the downscaling, or the disaggregation of the population, reported at municipality level ("source zones") to pixels ("target zones") using the dasymetric mapping technique [30] supported by LCLU data (COS or CLC). The second step (G) involved the summation of the inhabitants of urban agglomerations, within each municipality.

The model supporting the population disaggregation assumed that although most of the population is concentrated in urban areas, there is a small share living outside urban areas. Accordingly, the population was distributed by three land cover classes that are typically urban and by one non-urban class: Continuous urban fabric (111), Discontinuous urban fabric (112), Sports, leisure and cultural facilities, and historic zones (142) and Complex cultivation patterns (242). The inclusion of the latter class among the residential areas of the territory is due to the fact that these agricultural areas contain dispersed dwellings.

The ancillary datasets used in the disaggregation of the population at the municipality level are COS or CLC (alternatively). The usefulness of these datasets to the disaggregation process was improved through its reclassification into three categories (step D) more related to the distribution of the population for residential purposes in the territory. 


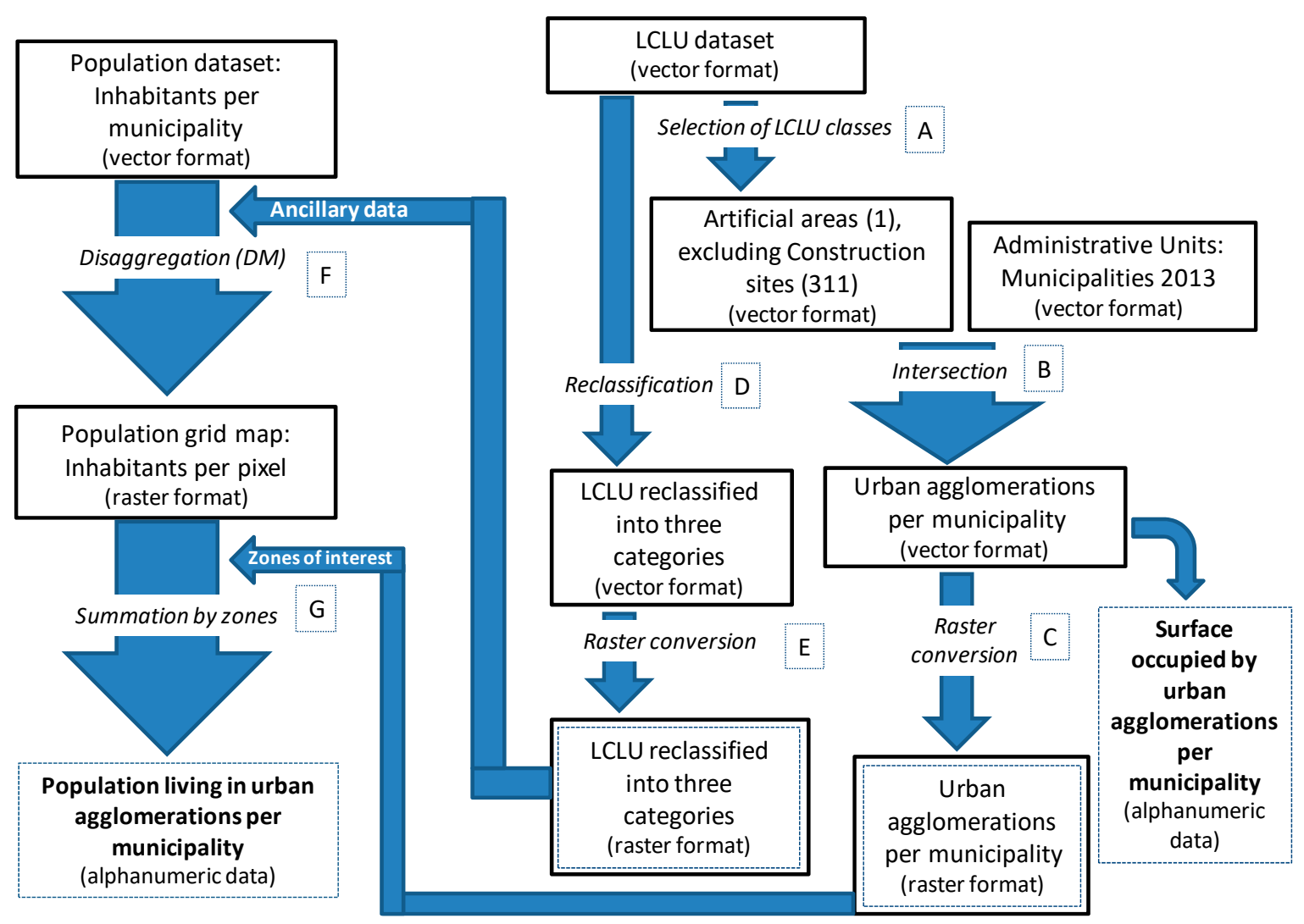

Figure 1. Workflow used to assess the surface occupied by urban agglomerations and the corresponding population, per municipality.

Category 1 -Composed by areas occupied by Continuous urban fabric (111) and Discontinuous urban fabric (112). This category should include the largest share of the territory population.

Category 2-Composed by areas occupied by Sports, leisure and cultural facilities, and historic zones (142) and by Complex cultivation patterns (242). This category should include a small proportion of the territory inhabitants.

Category 3-Composed by areas occupied by the remaining LCLU classes (not included in categories 1 e 2), this category represents all the uninhabited areas.

The vector datasets representing the three categories above described were later converted to raster format (step E). The size of the pixel used in the conversion varied with the data source: it corresponded to $25 \mathrm{~m}$ in the case of COS, and $100 \mathrm{~m}$ in the case of CLC. These pixel sizes were chosen based on the technical characteristics of the two LCLU products, namely the minimum distance between lines represented in both (20 $\mathrm{m}$ for COS and $100 \mathrm{~m}$ for CLC).

The adopted disaggregation process enables the assignment of rules for the allocation of inhabitants within the categories represented in the ancillary information. For this purpose, it was defined that the number of inhabitants to be allocated to category 1 could be freely estimated by dasymetric mapping. To control the allocation of inhabitants to category 2, a population density equal to 1.6 inhabitants per square kilometre was imposed. This value was selected after testing several alternative densities. To prevent the allocation of inhabitants to category 3 , a population density of zero inhabitants per square kilometre was imposed.

The outcome of step $\mathrm{F}$ is a population grid map that is more detailed than the population distribution per municipalities, initially available. This population grid map has a spatial resolution that varies with the ancillary dataset used-namely, $25 \mathrm{~m}$ if COS is employed or $100 \mathrm{~m}$ if CLC is employed. 
The population living in urban agglomerations per municipality (step G) is assessed by overlaying the population grid map with the urban agglomerations by municipalities grid map (dataset produced in $C$ representing the zones of interest) and by summing:

- the number of residents in each zone of interest and

- the number of residents in all zones of interest of each municipality.

\section{Results}

Given the higher thematic detail of COS, the use of COS was favoured over CLC to ensure more accurate results for Mainland Portugal. Accordingly, the results presented report the comparison of outcomes produced by COS and by CLC for 2011, the validation of the population estimates obtained for census years, and the LCRPGR and LUE estimates obtained using COS for two time-periods.

\subsection{Comparison of Results Produced by COS and by CLC for 2011}

As already mentioned, the single results produced by COS that are comparable with those obtained by CLC are estimates per municipality for 2011 of the population living in urban agglomerations and the surface occupied by urban agglomerations. These estimates are based on 2011 population per municipality and COS 2010 or CLC 2012, in alternative.

In what concerns the surface occupied by urban agglomerations, it stands out that the area estimated through COS is larger than that estimated by CLC, not only in most of the municipalities $(87.4 \%)$ but also in Mainland Portugal. Table 2 presents descriptive statistics on the surface occupied by urban agglomerations per municipality estimated by COS and by CLC. The last column of this table also presents descriptive statistics (relative to 278 municipalities) on the differences between COS and CLC estimates for each municipality. The major differences between COS and CLC estimates are justified by distinctive features of these datasets.

The higher thematic detail of $\operatorname{COS}(\mathrm{MMU}=1 \mathrm{ha}$ ) enables the identification of urban agglomerations that are not identified by CLC (MMU=25 ha), ergo the corresponding surface estimated through COS is higher than that estimated through CLC. However, in some municipalities, it was noted that the surface estimate provided by CLC is larger than that provided by COS. Most of these municipalities are part of Lisbon and Porto metropolitan areas. Such differences may have two causes: i) the higher thematic detail of COS allowed the identification of non-urban areas within the urban agglomerations identified through CLC, and ii) the LCLU classification may differ for some land cover/ land use types, namely for big urban or peri-urban parks, that are presently classified as Green urban areas (141) by CLC and as Forests (31) by COS. This is the case of Monsanto urban park that serves Lisbon.

Table 2. Descriptive statistics on the surface occupied by urban agglomerations estimated by COS and by CLC for 2011.

\begin{tabular}{|c|c|c|c|}
\hline $\begin{array}{l}\text { Surface Occupied by Urban } \\
\text { Agglomerations in } 2011\end{array}$ & COS Estimate $\left(\mathrm{Km}^{2}\right)$ & CLC Estimate $\left(\mathrm{Km}^{2}\right)$ & $\begin{array}{c}\text { Differences (COS-CLC } \\
\text { Estimate) }\left(\mathrm{Km}^{2}\right)\end{array}$ \\
\hline Mainland Portugal & 4315.7 & 3281.2 & 1034.5 \\
\hline Minimum per municipality & 0.9 & 0.4 & -18.5 \\
\hline Municipality Median & 9.8 & 5.8 & 2.9 \\
\hline Municipality Mean & 15.5 & 11.8 & 3.7 \\
\hline Maximum per municipality & 87.5 & 93.8 & 25.8 \\
\hline Municipality Standard Deviation & 15.0 & 14.7 & 4.8 \\
\hline
\end{tabular}

Considering that COS estimates a larger surface of urban agglomerations than CLC for most of the territory, the estimate of COS for the population living in those areas will be necessarily higher than the corresponding estimate of CLC. Table 3 confirms that COS estimated more 6059 inhabitants in urban agglomerations than CLC for Mainland Portugal. In most Mainland municipalities (83.8\%), COS led also to higher estimates than CLC. The main differences observed in Table 3 may also be justified by the differentiating factors of the LCLU datasets, above mentioned. 
Table 3. Descriptive statistics on the population living in urban agglomerations estimated by COS and by CLC for 2011.

\begin{tabular}{lccc}
\hline $\begin{array}{c}\text { Population Living in Urban } \\
\text { Agglomerations in 2011 }\end{array}$ & $\begin{array}{c}\text { COS Estimate } \\
\text { (Inhabitants) }\end{array}$ & $\begin{array}{c}\text { CLC Estimate } \\
\text { (Inhabitants) }\end{array}$ & $\begin{array}{c}\text { Differences (COS-CLC } \\
\text { Estimate) (Inhabitants) }\end{array}$ \\
\hline Mainland Portugal & 10044163 & 10038104 & 6059 \\
Minimum per municipality & 1834 & 1833 & -665 \\
Municipality Median & 15690 & 15584 & 12 \\
Municipality Mean & 36130 & 36108 & 22 \\
Maximum per municipality & 550693 & 551359 & 1049 \\
Municipality Standard Deviation & 58276 & 58292 & 87 \\
\hline
\end{tabular}

\subsection{Validation of the Population Grid Maps Produced for Mainland Portugal for Census Years}

The assessment of the accuracy of the population grid maps produced through dasymetric mapping requires the quantification of the disagreement between the population estimates and the true population values for a sample of sites. The disagreement between observed and estimated values can be reported using several quantitative parameters, such as the Total Absolute Error (TAE), the Mean Absolute Error (MAE), the Root Mean Square Error (RMSE), or the Pearson correlation coefficient. As previous studies $[17,35]$ have shown that TAE is more robust than RMSE in the presence of outliers or for skewed distributions, the parameter chosen in this study for quantifying the disagreement between the estimated and the observed values derives from TAE, and is designated Relative Total Absolute Error (RTAE).

RTAE evaluates the ratio between the sum of the absolute estimation deviations of the modelled variable and the sum of the known values of the same variable, for all the spatial units, according to the following expression.

$$
R T A E=\sum_{\mathrm{j}}\left|\mathrm{P}_{\mathrm{j}}^{\prime}-\mathrm{P}_{\mathrm{j}}\right| / \mathrm{P}
$$

where

$\mathrm{P}^{\prime}{ }_{\mathrm{j}}=$ Population estimate for the spatial unit

$P_{j}=$ Observed population for the spatial unit

$\mathrm{P}=$ Total population $=$ sum of observed population values for all spatial units

$j=$ Number of spatial units

The RTAE values can range from zero to two. An RTAE value of zero expresses a perfect fit of the estimates to the observed values. An RTAE value of two indicates ineffectiveness of the estimation model to reproduce the observed values.

Since municipalities were used as source zones, the estimates produced by dasymetric mapping for the municipalities equal the observed values, due to the volume-preserving property of the technique [30]. For this reason, the spatial unit used in the validation of each population grid map corresponds to the parish (also known as Land Administrative Units of level 2 (LAU2) in Portugal). The population estimates by parish were obtained by summing all pixel values within each parish. Given that the population, at the parish level, is only accurate in census years, the validation was just performed for population grid maps corresponding to the census years.

The following validation results, expressed as RTAE, refer to the whole territory (Mainland Portugal). The validation of the population grid map produced for 2011, using COS 2010, led to an RTAE value of 0.34 . An RTAE value of 0.43 was obtained for the equivalent grid map produced through CLC 2012. In the validation of the population grid map produced for 2001, using CLC 2000, an RTAE value of 0.46 was obtained.

As expected, RTAE values are lower when COS is used as ancillary information than when using CLC, due to the higher thematic detail provided by COS. As explained by Silva et al. [31], the RTAE values are strongly dependent on the difference in size between the source zones used to disaggregate population and the spatial units used for validation. The median area for Mainland municipalities is $220 \mathrm{~km}^{2}$, while that for 
parishes is $11 \mathrm{~km}^{2}$. Taking these facts into account, the RTAE values obtained in this study do not differ substantially from those described by similar works applied to Mainland Portugal [31].

Figure 2 presents the validation results of the population grid map produced for 2011 (using COS 2010 as ancillary data), by NUTS III regions. This figure depicts the RTAE variation across regions and enables the identification of those presenting higher RTAE values than the Mainland value (0.34), namely Alentejo Litoral (0.69), Alentejo Central (0.35), and Região de Leiria (0.46).

In Alentejo Litoral and Alentejo Central, there was an overestimation of the population, while in Região de Leiria, an underestimation took place.

Alentejo Litoral and Alentejo Central are low population density regions $\left(<23\right.$ Inhabitants $\left./ \mathrm{km}^{2}\right)$ where agricultural areas cover a significant part of the territory. The overestimation of its population may have resulted from the allocation of an exceeding number of inhabitants to agricultural areas (namely to the class of complex cultivation patterns). An explanation for the highest RTAE value obtained for Alentejo Litoral requires further investigation.

The underestimation of Região de Leiria population may be explained by the large share of inhabitants living in dispersed dwellings and by the fact that more than one half of the territory is covered by forest.

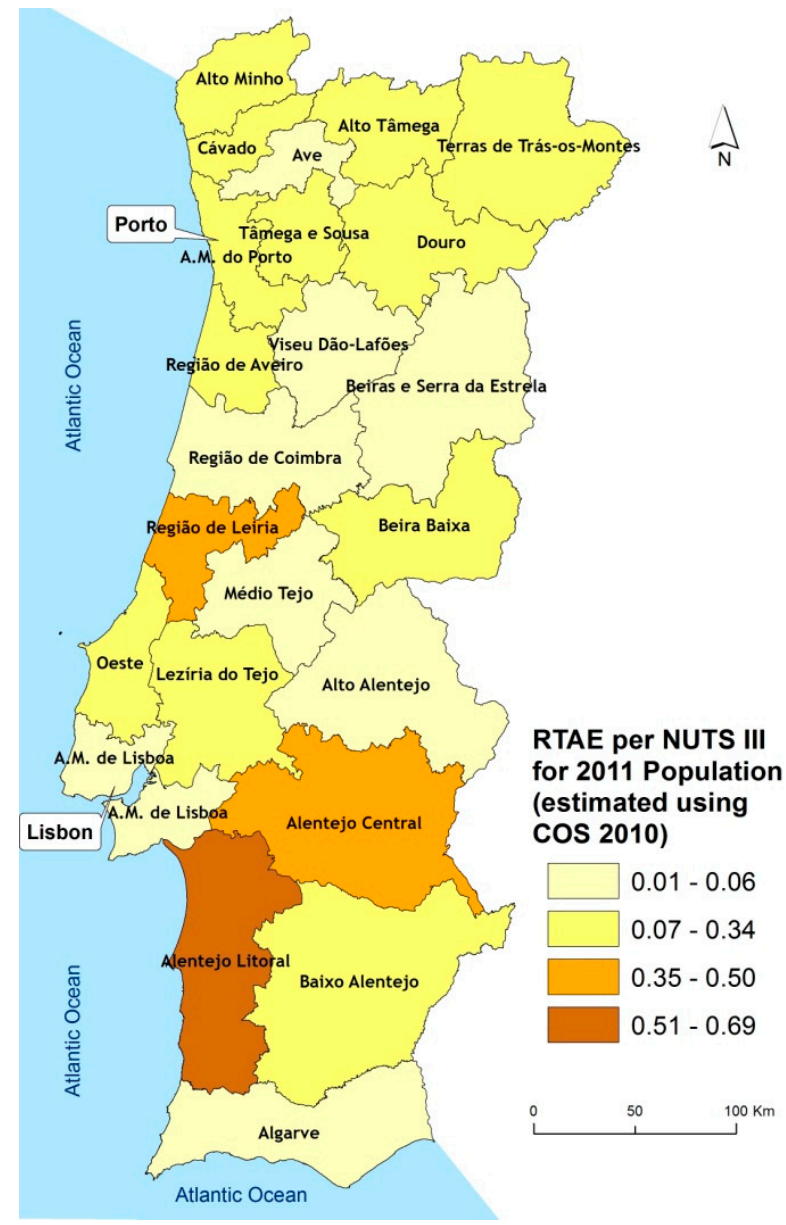

Figure 2. Validation results of the Population grid map produced for 2011 by NUTS III regions, expressed as Relative Total Absolute Error (RTAE).

\subsection{LCRPGR and LUE Indicators Estimated Through COS}

Considering that the work developed using COS may be replicated using CLC and that the indicators estimates obtained through COS are more accurate than those obtained by CLC, this section 
provides an analysis of the LCRPGR and LUE indicators estimated through COS for the periods 2007-2011 and 2011-2015.

Between 2007 and 2011, there was a general increase of the surface occupied by urban agglomerations in almost all the municipalities and in the Mainland. The soil consumption rate per municipality ranged from $-0.4 \%$ to $39.7 \%$. Mainland average soil consumption rate was $2.7 \%$. In the same period, most of the municipalities $(74 \%)$ lost urban population, while a small increase of urban population $(0.04 \%)$ took place in the Mainland. The urban population growth rate per municipality ranged from $-8.1 \%$ to $10 \%$. Figure 3 a reveals that the population loss trend did not affect some of the municipalities closer to the coastline and most of those belonging to Lisbon and Porto metropolitan areas.

In the period 2011-2015, the surface occupied by urban agglomerations increased in almost all the municipalities and in the Mainland, at a pace similar to that observed in 2007-2011. In the same period, almost all the municipalities (90\%) lost residents in urban areas, just as in the Mainland. Figure $3 \mathrm{~b}$ shows that the few municipalities that have not lost urban population are concentrated in the Lisbon Metropolitan Area and in the northwest ribbon of the Mainland.

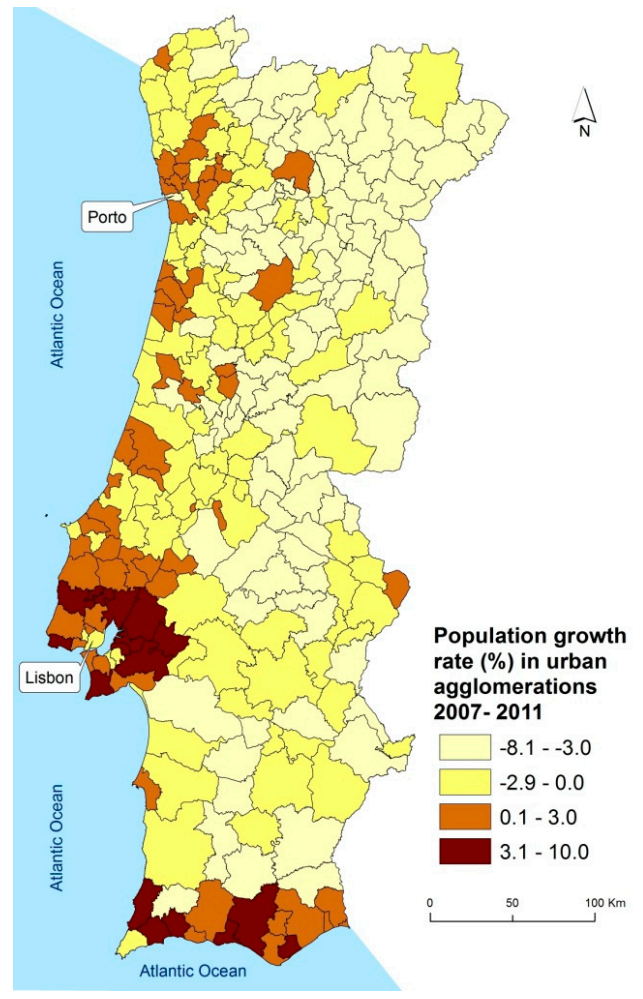

(a)

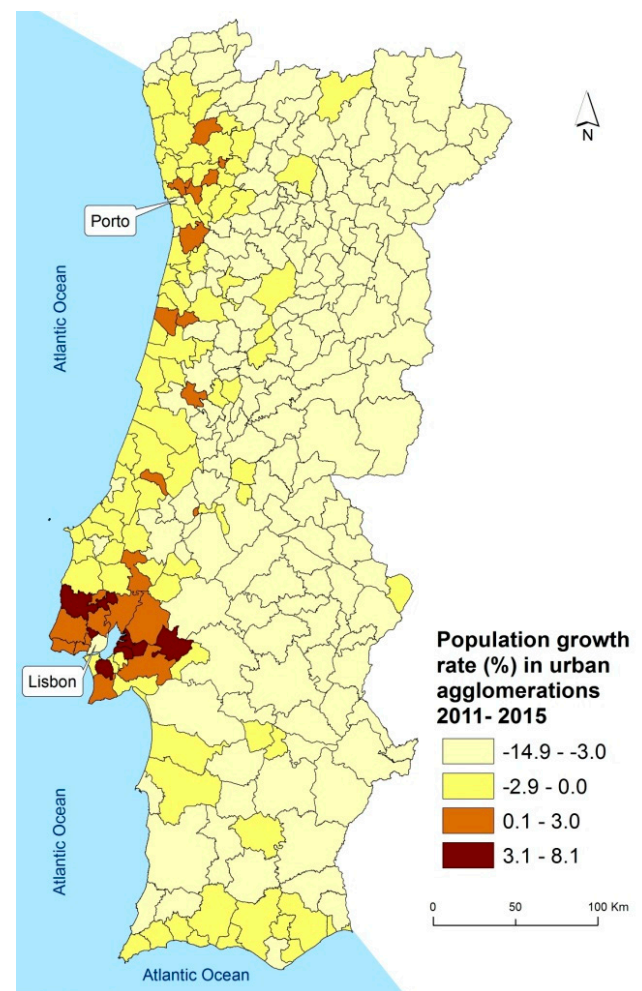

(b)

Figure 3. Population growth rate in urban agglomerations per municipality (\%) for 2007-2011 (a) and 2011-2015 (b).

Table 4 characterises the LCRPGR estimates obtained for the periods 2007-2011 and 2011-2015. The LCRPGR estimate obtained for the Mainland in 2007-2011 (64.4) is clearly greater than one, reflecting the simultaneous increase of the population growth rate and soil consumption rate, with a faster soil consumption than the population growth. Similar variations to that described for the Mainland (LCRPGR > 1) also took place in about $16 \%$ of the municipalities.

As shown in Figure 4a, the LCRPGR estimates for the period 2007-2011 are negative in most municipalities $(72 \%)$. In these municipalities, the area occupied by urban agglomerations increased, while the corresponding population decreased.

A small proportion of the municipalities (12\%) show LCRPGR estimates varying between zero and one. In most of these municipalities, a simultaneous increase of the population growth rate and 
the soil consumption rate did also happen; however, the urban soil consumption was slower than the population growth.

Table 4. Characterisation of the LCRPGR estimates produced by COS for the periods 2007-2011 and 2011-2015.

\begin{tabular}{lcc}
\hline LCRPGR & 2007-2011 & 2011-2015 \\
\hline Mainland Portugal & 64.4 & -1.3 \\
Minimum per municipality & -43.4 & -15.5 \\
Municipality Median & -0.3 & -0.4 \\
Municipality Mean & -0.8 & 1.0 \\
Maximum per municipality & 53.5 & 448.6 \\
Municipality Standard Deviation & 7.2 & 27.3 \\
\% of Municipalities with LCRPGR $<0$ & 71.9 & 86.7 \\
\% of Municipalities with 0 $\leq$ LCRPGR $\leq 1$ & 11.9 & 8.6 \\
\% of Municipalities with LCRPGR $>1$ & 16.2 & 4.7 \\
\hline
\end{tabular}

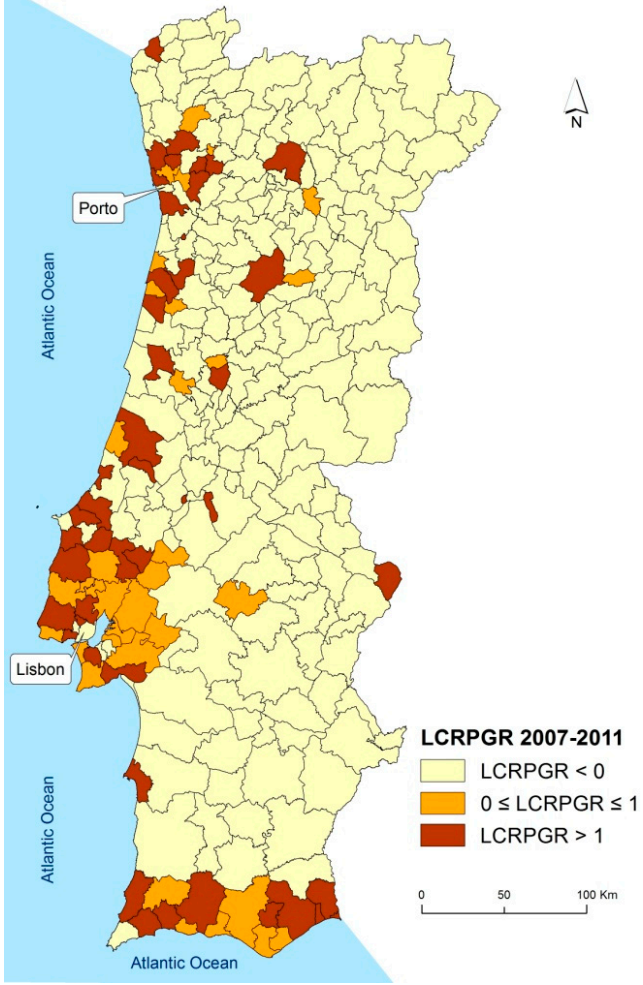

(a)

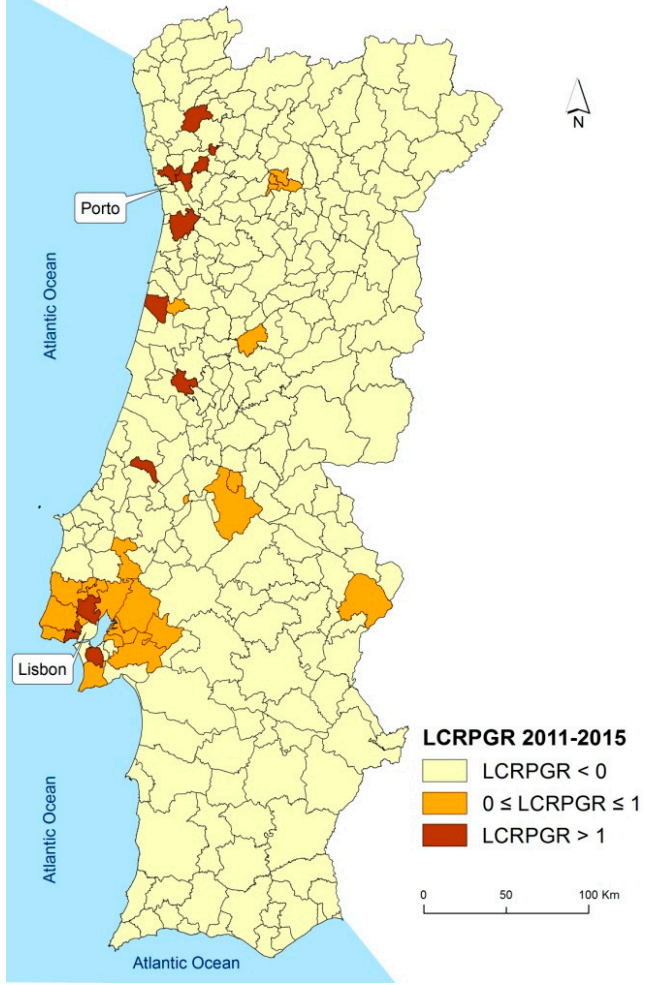

(b)

Figure 4. LCRPGR estimates per municipality for 2007-2011 (a) and 2011-2015 (b).

In the period 2011-2015, the proportion of municipalities that presented a negative estimate of LCRPGR was higher (87\%) compared to 2007-2011. The Mainland LCRPGR estimate for 2011-2015 was also negative (-1.3), as a result of the urban soil consumption increase combined with urban population reduction. Comparatively to 2007-2011, the number of municipalities with LCRPGR estimates above the unit did also decrease. Accordingly, the LCRPGR estimates for the period 2011-2015 are negative in almost all the territory, as illustrated in Figure $4 \mathrm{~b}$.

Table 5 characterises the LUE estimates obtained for the periods 2007-2011 and 2011-2015. In these periods the LUE estimates were negative both in the Mainland and in most municipalities. In the Portuguese context, the negative values of the LUE are explained by the expansion of urban areas accompanied by the decrease of the urban residents. 
Compared to the previous period, in 2011-2015, not only the Mainland but also a higher number of municipalities lost urban residents, so the proportion of municipalities presenting positive estimates of LUE was halved. Positive values of LUE indicate that urban soil consumption was slower than urban population growth in the period under review.

Table 5. Characterisation of the LUE estimates produced by COS for the periods 2007-2011 and 2011-2015.

\begin{tabular}{lcc}
\hline LUE & 2007-2011 & 2011-2015 \\
\hline Mainland Portugal & -0.07 & -0.12 \\
Minimum per municipality & -1.18 & -1.62 \\
Municipality Median & -0.10 & -0.16 \\
Municipality Mean & -0.13 & -0.19 \\
Maximum per municipality & 0.14 & 0.15 \\
Municipality Standard Deviation & 0.16 & 0.19 \\
\% of Municipalities with LUE $<0$ & 89.2 & 94.6 \\
\% of Municipalities with LUE $\geq 0$ & 10.8 & 5.4 \\
\% of Municipalities with -0.03 $\leq$ LUE $\leq 0.03$ & 13.3 & 5.0 \\
\hline
\end{tabular}

In 2011-2015, the proportion of municipalities presenting LUE estimates ranging from -0.03 to 0.03 did also fall compared to 2007-2011. Values of LUE around zero arise when soil consumption per capita is stable over the period under review. This may also mean that the urban surface and the urban population increased or decreased both at the same rate. Figure 5a,b show the spatial dominance of the negative LUE estimates and the decrease of positive LUE values between the two periods under analysis.

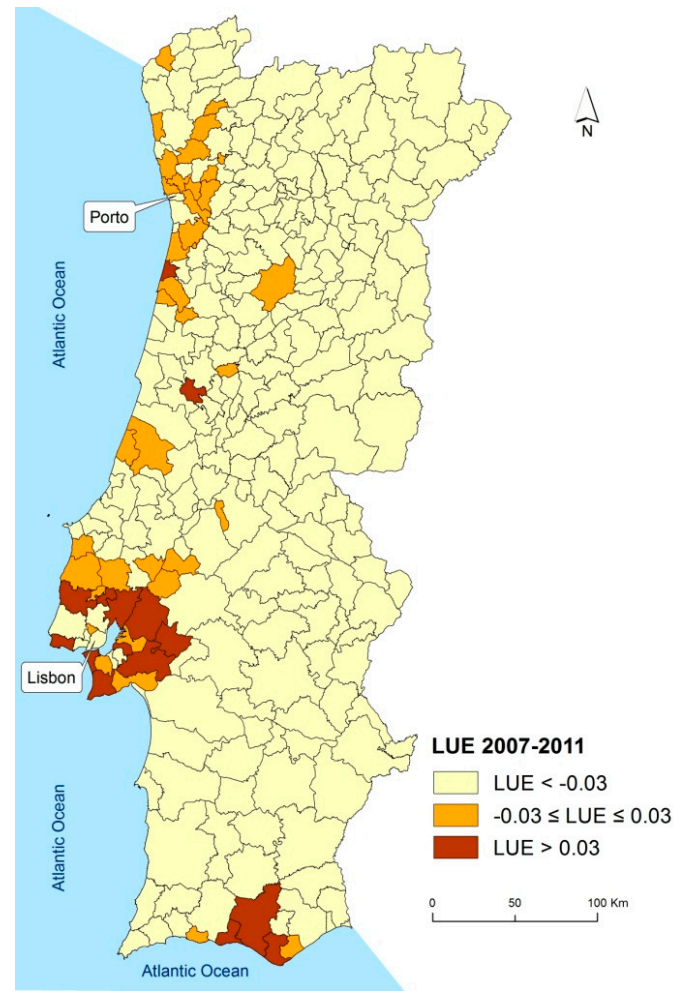

(a)

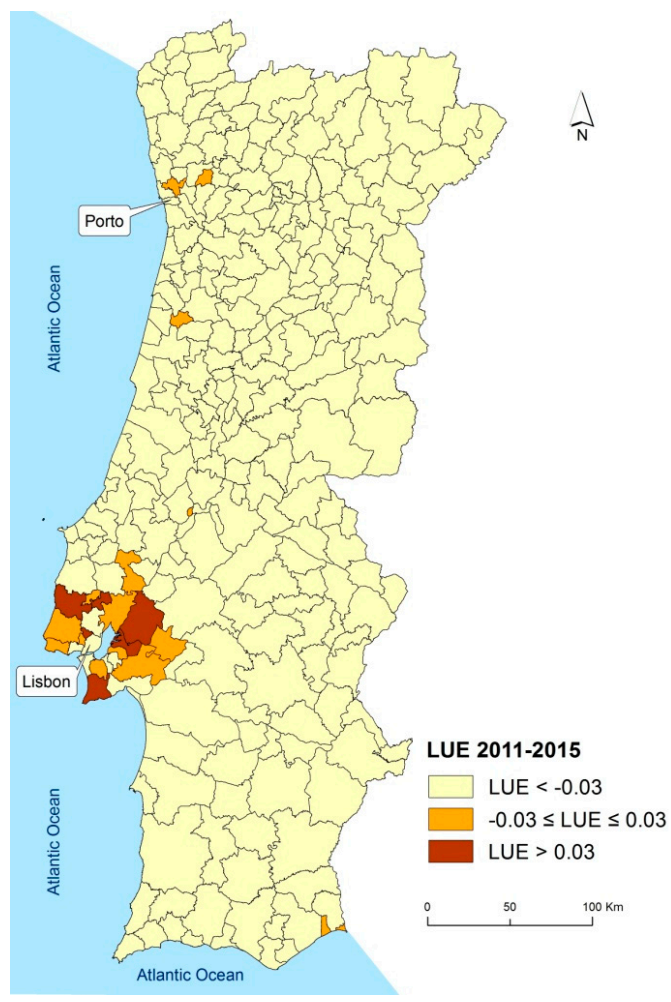

(b)

Figure 5. LUE estimates per municipality for 2007-2011 (a) and 2011-2015 (b).

The results of the LCRPGR and LUE estimates obtained for the periods 2007-2011 and 2011-2015 mirror the Portuguese demographic evolution shown in Figure 6. The negative population growth 
experienced in Portugal since 2010 is not as noticeable in $2007-2011$ as in the following period, which presents negative effective growth rates resulting from the combination of negative natural and migratory balances. During 2011-2015, the country faced an economic and social crisis peaking in 2013, which led to the emigration of a significant proportion of unemployed and young population. Population ageing, as well as the increase in longevity and the fall of birth rate since 2000, are additional features that explain the observed population loss.

Considering that the majority of the population has an evolution as depicted in Figure 6 and resides in urban areas, it is assumed that such evolution is equally representative of the evolution of urban inhabitants.

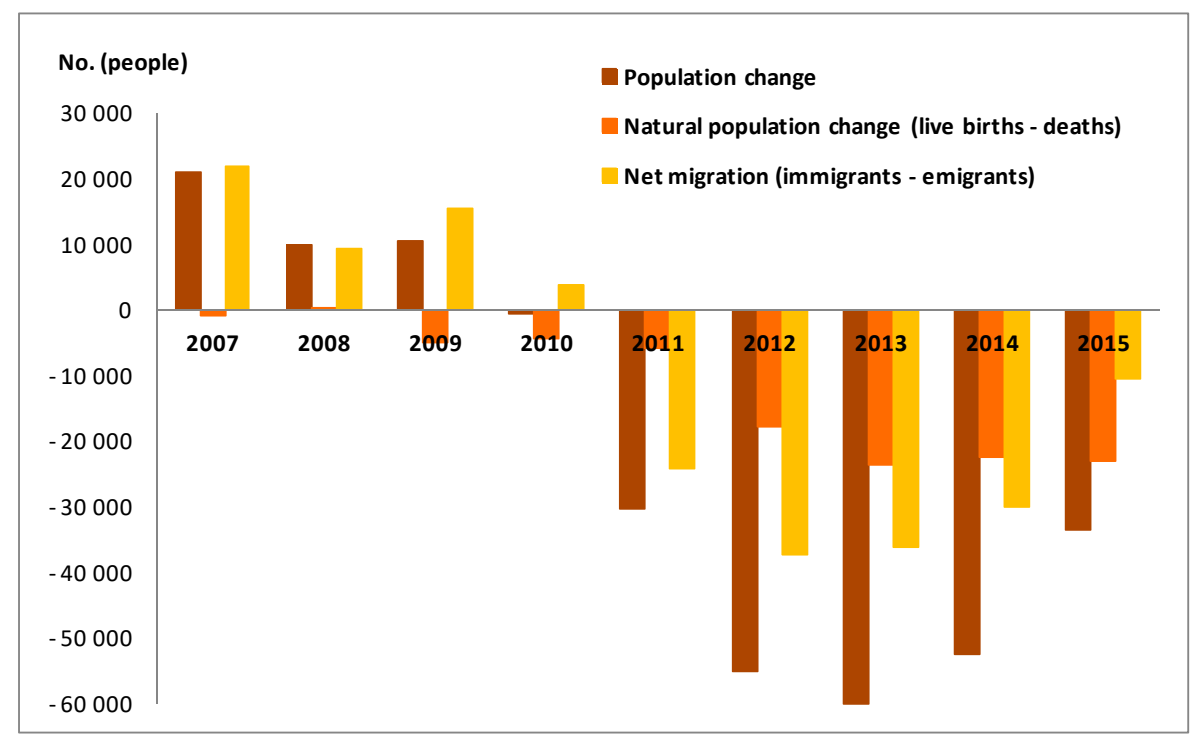

Figure 6. Portuguese demographic evolution 2007-2015 (Data source: Statistics Portugal).

\section{Discussion}

The primary contribution of this work materialises in a methodological approach designed to assess the ratio of land consumption rate to population growth rate. Regardless of the formula adopted, both the surface occupied by urban areas and their population are evaluated herein at different temporal instants. The applicability of this methodology depends only on the availability of ancillary data, which enable the identification of urban areas and support the population disaggregation required for the estimation of the inhabitants in each urban area.

Some confusion does exist regarding the land type addressed by the indicator 11.3.1, as a consensus on its definition has not yet been reached. Given that the indicator is associated to the SDG 11 ("Make cities inclusive, safe, resilient and sustainable") and to the Goal 11.3 ("By 2030, enhance inclusive and sustainable urbanization and capacity for participatory, integrated and sustainable human settlement planning and management in all countries"), the authors assume that the land type addressed by the indicator is urban land comprising both the built-up areas and the open urban space. Urban development often sacrifices different non-urban land types (e.g. agricultural, forestry). The quantification of these non-urban land types is an independent process that can be performed at a later stage.

The spatial unit adopted to represent urban land was the urban agglomeration, as described by the UN-Habitat in 2009 [34]. Taking into account the input datasets used to define urban areas (LCLU maps), a selection of the most representative land cover/ land use classes was made. The LCLU classes chosen to represent urban agglomerations were the Artificial areas (1) excluding Construction sites (311). Although this exclusion may not be consensual, it was grounded in the knowledge that when the construction activity ends, the construction sites do not always become urban fabric. However, 
the authors admit that other classes, such as Mineral extraction sites (131) or Waste disposal areas (132), could have also been excluded.

In some studies, identified in the literature $[4,9]$ the surface occupied by the artificial area class is used to estimate the urban expansion, while in other studies the UMZ units [26-28] or the surface of spatial units categorized as urban $[5,8,10]$ are employed with the same purpose. Compared to some of these studies $[4,9,26-28]$, the land cover classes selected in our study to define urban areas are less comprehensive, contributing thus to a more conservative estimate of urban land consumption.

In what concerns the population growth estimates, in most common approaches $[8,9,11]$, urban and non-urban residents are not differentiated, and the urban inhabitants may be represented by the residents in administrative or census units to which urban areas appertain. In other studies [5,36], urban inhabitants are estimated based on population grid maps that provide a spatial disaggregation of the population data commonly associated with administrative or census units. The latter is the approach followed by our study. In fact, we had to produce new population grid maps because those that are available at the European level [17,31-33] present insufficient resolution for the estimation of residents in Portuguese urban areas.

The model that supported the population disaggregation was chosen from several alternative models, due to its best performance with the COS datasets. In this model, the LCLU classes are grouped into categories and some assumptions are made on those eligible as residential areas. Additionally, it allows us to control the allocation of inhabitants to specific categories by imposing population density thresholds.

The same base model was adopted for all the years used for population disaggregation because there was no evidence of model variability within the COS reference years $(2007,2010$, and 2015).

Since CLC provides a lower level of detail than COS, some of our model assumptions need to be adjusted to the CLC context. As explained by Gallego et al. [17], any CLC class may contain some residential areas; however, these areas are not mapped, because they correspond to urban patches with less than 25 ha. Therefore, their work enabled the allocation of inhabitants to more LCLU classes than our study.

Similarly to our study, in the population estimation calculated for the Urban Atlas polygons in 2013 [36], it was considered that most of the population lived in urban fabric classes, though admitting that a very small share of the population might live in other land cover classes. For these residual residential areas, our study did comprise less land cover classes than those selected by Silva et al. [36], but this is only due to the use of different ancillary data.

The choice of the LCLU classes included in each category was grounded in the authors' knowledge about COS and the population distribution in Mainland Portugal. In other countries and/or when using different ancillary data, the categories chosen may need to be rethought.

In view of the foregoing, the authors support the idea that the models adopted to disaggregate the population can vary both with the spatial resolution of the ancillary information and the time periods for which such information is available.

Although this study relied on data extracted from LCLU maps (COS or CLC), other datasets describing land cover/ land use could have been used as ancillary data (e.g. information on the soil sealing degree or a mix of different LCLU datasets $[17,36])$.

The accuracy of the estimates obtained in this study for the urban agglomerations surface depends mostly on the spatial resolution of the ancillary dataset and on the LCLU classes selected to represent the urban agglomerations. The accuracy of the values estimated for the urban inhabitants does also depend on the above-mentioned factors, as well as on the model and the assumptions that supported the population spatial redistribution. Furthermore, the temporal mismatch between LCLU data and the population data, as well as the absence of information on the buildings height, may contribute to the underestimation or overestimation of the population living in urban agglomerations.

Since true values are unknown, the validation of estimates is extremely difficult and its assessment using definitions, assumptions and approaches that are diverse from those adopted may lead to very 
different estimates from those reported herein. While keeping the same methodological approach, the authors are planning to test the soil sealing degree, as an alternative to COS, to understand how different ancillary datasets may influence obtained estimates.

With regard to the formulations used to assess the indicator 11.3.1, LCRPGR can lead to indeterminate values-although presented results did not allow their demonstration. As shown by the assessment of the indicator for the UK [8], the calculation of LCRPGR is not possible for spatial units where the number of residents has not changed over the studied period. In addition, when the information on the evolution of the land consumption and the population growth is not previously known, the interpretation of LCRPGR can be ambiguous. For example, LCRPGR values below zero may correspond to two opposite evolutions: population increase/ land consumption decrease or population decrease/ land consumption increase. The inadequacy of LCRPGR for monitoring the phenomenon of interest, as well as the difficulties on its interpretation, have also been reported by others authors [13]. Comparatively to LCRPGR, the interpretation of LUE is straightforward. Moreover, LUE proved to be better suited to monitor the urban development phenomenon.

Probably due to these facts and to the dimensionless nature of the LCRPGR indicator, the presentations on the assessment of the indicator 11.3 .1 made by several countries $[8,9,11]$ report the urban expansion and the population growth rate in terms of percentage changes instead of using LCRPGR values. The work developed by Melchiorri et al. [5] constitutes an exception to the foregoing.

While the results obtained in this study for municipalities are more useful for an internal debate, the results respecting the Mainland enable comparisons with other countries. The estimates on the proportion of Mainland surface occupied by urban areas ranged from 4.7\% (in 2007) to 5\% (in 2015). The urban expansion rate (2.7\%) was identical in the two periods studied (2007-2011 and 2011-2015). The urban population increased slightly $(0.04 \%)$ in the first period and decreased $(-2.1 \%)$ in the second period. Accordingly, a general decrease in the values of LCRPGR and LUE was observed between both periods. The LCRPGR estimate decreased from 64.4 in 2007-2011 to -1.3 in 2011-2015 and the LUE estimate decreased from -0.07 to -0.12 in the same periods. The validation of these estimates is unfeasible due to the lack of alternative works tackling 11.3.1 for Mainland Portugal.

Although the coarse spatial resolution of the datasets used by Melchiorri et al. [5] does not allow detailed country-level assessments, these authors identified specific locations of the globe showing LCRPGR estimates (for the period 1990-2015) matching the range of our estimates. Their study reports that substantially negative LCRPGR values $(<-1)$ were found in central and western European countries, and LCRPGR values ranging from -1 to 0 were also found in Europe-most especially in eastern European countries.

The Environmental Indicator Report produced by the EEA for 2017 [4] presents an estimate of 0.52\% (percentage of 2006 artificial land) for the Portuguese mean annual land take in 2006-2012. Similar estimates on land take were obtained for countries such as Montenegro $(0.55 \%)$, Poland $(0.49 \%)$ and France (0.47\%) [4].

The EEA estimate reported for Portugal is slightly lower than the one that can be derived from our results for 2007-2011 (0.7\%). The following factors may explain the discrepancy between both estimates:

(a) The estimate produced by our study did not include the Madeira and the Azores autonomous regions, which were included in the EEA study;

(b) The evaluation periods are not quite the same;

(c) In the EEA study, the urban areas are represented by artificial areas, while in our study they are represented by artificial areas excluding construction sites; and

(d) The estimates were obtained using different data sources. While the EEA estimate is based on CLC land cover changes, our estimate is based on COS land cover changes.

\section{Conclusions}

The methodological approach proposed in the present work for the assessment of the indicator 11.3.1 enabled the description and discussion of definitions and assumptions adopted for its 
implementation, as well as the identification of the limitations associated with the techniques and datasets used. Furthermore, two alternative mathematical expressions (LCRPGR and LUE) were tested producing estimates for the indicator at the municipality level, in Portugal.

The study provides evidence for the following: (i) the computation of the ratio of land consumption rate to population growth rate through the formula currently proposed by the UN-Habitat (LCRPGR) is not always feasible and (ii) the interpretation of its results is not straightforward.

In fact, the formulation based on Land Use Efficiency (LUE) is considered more suitable for monitoring urban development and for capturing urban areas dynamics, besides being easier to interpret than LCRPGR.

The results of LCRPGR and LUE obtained for the two periods under analysis show that while the urban areas increased in the majority of the Portuguese municipalities, their population decreased, leading to negative values of both indicators in most of the Mainland territory. In view of the decline of the Portuguese population since 2010 and the decrease of urban population in most municipalities, the widespread expansion of the national urban areas is not fully understood, requiring a more in-depth analysis of its growth patterns and inherent processes. Such analysis must be carried out at the municipality level, which is the level at which urban planning policies are defined. On the other hand, in those municipalities whose urban population showed a growth trend, decision-makers need to be made aware of the need to implement more sustainable land use policies to control urban sprawl.

The by-products of the work developed consist of maps depicting the distribution of the resident population in Mainland Portugal with a better spatial resolution than those currently available, which will be useful beyond the scope of this work.

Extension of this work planned for the short-term include:

- a sensitivity analysis to shed light on how the values estimated for the indicator vary with different combination of land cover classes;

- the assessment of the population estimate accuracy by LCLU classes for improving the modelling of population data; and

- the comparison of estimates herein obtained with those produced using the soil sealing degree layer as ancillary dataset.

The work developed intends to support the ongoing debate about the indicator 11.3.1, held by the European Work Group on Data Integration of the United Nations Initiative on Global Geospatial Information Management (UN-GGIM: Europe). Since the indicator 11.3.1 is related to some of the indicators proposed by the European Commission to monitor the contribution of the EU policies and initiatives for the implementation of the SDG— the EU SDG indicator set [37] - namely the EU SDG indicators 15.21 (Artificial land cover per capita) and 15.24 (Change in artificial land cover per year), it is expected that this work will also be useful to the working groups involved in their estimation.

Author Contributions: Formal analysis, R.N. and J.D.; Research, R.N., J.D., M.C., and J.M.C.P.; Methodology, R.N., J.D. and M.C.; Project administration, J.M.C.P.; Supervision, M.C.; Validation, R.N.; Writing-original draft, R.N.; Writing-review \& editing, R.N., J.D., M.C. and J.M.C.P.

Funding: This research was funded by Fundação para a Ciência e Tecnologia (FCT), under the grant number PTDC/AGR-FOR/2586/2014, assigned to the project RURINTFIRE- Fire in the Rural-Urban Interface: characterisation, risk mapping, and fuel break design.

Acknowledgments: CEF is the Portuguese research unit, funded by Fundação para a Ciência e a Tecnologia (UID/AGR/00239/2013), that provided the necessary conditions for the development of this study. The authors acknowledge the use of the Intelligent Dasymetric Mapping (IDM) Toolbox for ArcGIS 10.3 provided by the United States Environmental Protection Agency and are grateful to Megan Culler for all the technical support on the use of IDM Toolbox. The authors are also grateful to Filipe Marcelino and Cristina Igreja, from DGT, for their useful suggestions on Mainland land cover/ land use issues.

Conflicts of Interest: The authors declared no potential conflict of interest with respect to the research, authorship, and/or publication of this article. The founding sponsors had no role in the design of the study; in the collection, analyses, or interpretation of data; in the writing of the manuscript, and in the decision to publish the results. 


\section{Appendix A}

Table A1. COS and CLC Nomenclature: Levels 1, 2 and 3.

\begin{tabular}{|c|c|c|}
\hline Level 1 & Level 2 & Level 3 \\
\hline \multirow{4}{*}{ Artificial areas (1) } & Urban fabric (11) & $\begin{array}{l}\text { Continuous urban fabric (111) } \\
\text { Discontinuous urban fabric (112) }\end{array}$ \\
\hline & $\begin{array}{l}\text { Industrial, commercial and } \\
\quad \text { transport units (12) }\end{array}$ & $\begin{array}{c}\text { Industrial and commercial units and general infrastructure (121) } \\
\text { Road and rail network and associated land (122) } \\
\text { Port areas (123) } \\
\text { Airports (124) }\end{array}$ \\
\hline & $\begin{array}{l}\text { Mineral extraction, waste disposal } \\
\text { and construction sites (13) }\end{array}$ & $\begin{array}{c}\text { Mineral extraction sites (131) } \\
\text { Waste disposal areas (132) } \\
\text { Construction sites (133) }\end{array}$ \\
\hline & $\begin{array}{c}\text { Green urban areas, sports, leisure } \\
\text { and cultural facilities, } \\
\text { and historic zones (14) }\end{array}$ & $\begin{array}{c}\text { Green urban areas (141) } \\
\text { Sports, leisure and cultural facilities, and historic zones (142) }\end{array}$ \\
\hline \multirow{4}{*}{$\begin{array}{l}\text { Agricultural and } \\
\text { agro-forestry areas (2) }\end{array}$} & Arable land (21) & $\begin{array}{l}\text { Non-irrigated arable land (211) } \\
\text { Irrigated arable land (212) } \\
\text { Rice fields (213) }\end{array}$ \\
\hline & Permanent crops (22) & $\begin{array}{l}\text { Vineyards (221) } \\
\text { Orchards (222) } \\
\text { Olive groves (223) } \\
\end{array}$ \\
\hline & Permanent pastures (23) & Permanent pastures (231) \\
\hline & $\begin{array}{l}\text { Heterogeneous } \\
\text { agricultural areas (24) }\end{array}$ & $\begin{array}{c}\text { Arable land and/or pastures associated with permanent crops (241) } \\
\text { Complex cultivation patterns (242) } \\
\text { Agriculture with natural and semi-natural vegetation (243) } \\
\text { Agro-Forestry Systems - AFS- (244) }\end{array}$ \\
\hline \multirow{3}{*}{$\begin{array}{l}\text { Forests and natural and } \\
\text { semi-natural areas (3) }\end{array}$} & Forests (31) & $\begin{array}{l}\text { Broad-leaved forests (311) } \\
\text { Coniferous forests (312) } \\
\text { Mixed forests (313) }\end{array}$ \\
\hline & $\begin{array}{l}\text { Open forests, shrubs and } \\
\text { herbaceous vegetation ( } 32 \text { ) }\end{array}$ & $\begin{array}{c}\text { Natural herbaceous vegetation (321) } \\
\text { Shrublands (322) } \\
\text { Sclerophyllous vegetation (323) } \\
\text { Open forests, clearcuts and young plantations (324) }\end{array}$ \\
\hline & $\begin{array}{l}\text { Open spaces with little or } \\
\text { no vegetation (33) }\end{array}$ & $\begin{array}{l}\text { Beaches, dunes and sand plains (331) } \\
\text { Bare rock (332) } \\
\text { Sparsely vegetated areas (333) } \\
\text { Burnt areas (334) }\end{array}$ \\
\hline \multirow{2}{*}{ Wetlands (4) } & Inland wetlands (41) & $\begin{array}{l}\text { Inland marshes }(411) \\
\text { Peat bogs (412) }\end{array}$ \\
\hline & Coastal wetlands (42) & $\begin{array}{c}\text { Salt marshes (421) } \\
\text { Salines and coastal aquaculture (422) } \\
\text { Intertidal flats (423) }\end{array}$ \\
\hline \multirow{2}{*}{ Water bodies (5) } & Inland waters (51) & $\begin{array}{l}\text { Water courses ( } 511) \\
\text { Water bodies }(512)\end{array}$ \\
\hline & Marine and coastal waters (52) & $\begin{array}{l}\text { Coastal lagoons }(521) \\
\text { Rivers mouths (522) } \\
\text { Ocean }(523)\end{array}$ \\
\hline
\end{tabular}

\section{References}

1. UN-Habitat. Sustainable Development Goal 11+ Make Cities and Human Settlements Inclusive, Safe, Resilient and Sustainable: A Guide to Assist National and Local Governments to Monitor and Report on SDG Goal 11+ Indicators. Monitoring Framework-Definitions-Metadata-UN-Habitat Technical Support. 2018. Available online: https://smartnet.niua.org/sites/default/files/resources/sdg_goal_11_monitoring framework.pdf (accessed on 15 July 2018).

2. Seto, K.C.; Fragkias, M.; Guneralp, B.; Reilly, M.K. A Meta-Analysis of Global Urban Land Expansion. PLOS ONE 2011, 6, e23777. [CrossRef] [PubMed]

3. Seto, K.C.; Guneralp, B.; Hutyra, R. Global forecasts of urban expansion to 2030 and direct impacts on biodiversity and carbon pools. PNAS 2012, 109, 16083-16088. [CrossRef] [PubMed]

4. European Environment Agency. Environmental Indicator Report 2017. Annual Indicator Report Series (AIRS)—In Support to the Monitoring of the 7th Environment Action Programme, EEA Report No. 21/2017. Available online: https:/ / www.eea.europa.eu/airs/2017 (accessed on 2 November 2018).

5. Melchiorri, M.; Pesaresi, M.; Florczyk, A.J.; Corbane, C.; Kemper, T. Principles and Applications of the Global Human Settlement Layer as Baseline for the Land Use Efficiency Indicator-SDG 11.3.1. Preprints 2018. [CrossRef] 
6. European Commission. Global Human Settlement. 2018. Available online: https://ghsl.jrc.ec.europa.eu/ datasets.php (accessed on 15 July 2018).

7. Pesaresi, M.; Ehrlich, D.; Ferri, S.; Florczyk, A.J.; Freire, S.; Halkia, S.; Julea, A.M.; Kemper, T.; Soille, P.; Syrris, V. Operating Procedure for the Production of the Global Human Settlement Layer from Landsat Data of the Epochs 1975, 1990, 2000, and 2014; EUR 27741 EN; Publications Office of the European Union: Luxembourg, 2016. [CrossRef]

8. UK Office for National Statistics. Using Innovative Methods to Report Against the Sustainable Development Goals. Available online: https://www.ons.gov.uk/economy/environmentalaccounts/ articles/usinginnovativemethodstoreportagainstthesustainabledevelopmentgoals/2018-10-22 (accessed on 1 November 2018).

9. Ministère de la Transition Écologique et Solidaire. Observation et Statistiques. Indicateurs Nationaux de Suivi de la Transition Écologique vers un Développement Durable (2015-2020): Artificialisation des Sols. Available online: http:/ / www.statistiques.developpement-durable.gouv.fr/indicateurs-indices/f/2491/ 0/artificialisation-sols-1.html (accessed on 1 November 2018).

10. Istituto Nazionale di Statistica (Istat). Rapporto SDGS 2018. Informazioni Statistiche per L'agenda 2030 in Italia. Prime Analisi; Istituto Nazionale di Statistica: Roma, Italia, 2018; ISBN 978-88-458-1961-2. Available online: https:/ / www.istat.it/it/ files/2018/07/SDGs.pdf (accessed on 1 November 2018).

11. National Administrative Department of Statistics (DANE). Use of Satellite Images to Calculate Statistics on Land Cover and Land Use. 2016. Available online: http:/ / cepei.org/wp-content/uploads/2016/08/reportpilot-project-colombia-v3.pdf (accessed on 2 November 2018).

12. Mwaniki, D. Module 3: Indicator 11.3.1 Land Consumption Rate to Population Growth Rate. Lecture Presented at the Regional Training Workshop on Human Settlement Indicators, Bangkok, Thailand, 26-29 March 2018. Available online: https://www.unescap.org/sites/default/files/Module\%203_ Land\%20Consumption\%20Rate\%20to\%20Population\%20Growth\%20Rate\%20for\%20indicator\%2011.3.pdf (accessed on 2 November 2018).

13. Corbane, C.; Politis, P.; Siragusa, A.; Kemper, T.; Pesaresi, M. LUE User Guide: A Tool to Calculate the Land Use Efficiency and the SDG 11.3 Indicator with the Global Human Settlement Layer; Publications Office of the European Union: Luxembourg, 2017; ISBN1 978-92-79-73631-5. ISBN2 8-92-79-73630-8. Available online: http:/ / publications.jrc.ec.europa.eu/repository/bitstream/JRC108026/lue_userguide_09082017_ online.pdf (accessed on 15 July 2018).

14. Diksha; Kumar, A. Analysing urban sprawl and land consumption patterns in major capital cities in the Himalayan region using geoinformatics. Appl. Geogr. 2017, 89, 112-123. [CrossRef]

15. Sharma, L.; Pandey, P.C.; Nathawat, M.S. Assessment of land consumption rate with urban dynamics change using geospatial techniques. J. Land Use Sci. 2012, 7, 135-148. [CrossRef]

16. Li, X.; Zhao, L.; Li, D.; Xu, H. Mapping Urban Extent Using Luojia 1-01 Nighttime Light Imagery. Sensors 2018, 18, 3665. [CrossRef] [PubMed]

17. Gallego, J.; Batista, F.; Rocha, C.; Mubareka, S. Disaggregating population density of the European Union with CORINE land cover. Int. J. Geogr. Inf. Sci. 2011, 25, 2051-2069. [CrossRef]

18. Salvati, L.; Sateriano, A.; Bajocco, S. To grow or to sprawl? Land Cover Relationships in a Mediterranean City Region and implications for land use management. Cities 2013, 30, 113-121. [CrossRef]

19. Salvati, L.; Tombolini, I.; Ippolito, A.; Carlucci, M. Land quality and the city: Monitoring urban growth and land take in 76 Southern European metropolitan areas. Environ. Plan. B Urban Anal. City Sci. 2018, 45, 691-712. [CrossRef]

20. Cegielska, K.; Noszczyk, T.; Kukulska, A.; Szylar, M.; Hernik, J.; Dixon-Gough, R.; Jombach, S.; Valánszki, I.; Kovács, K.F. Land use and land cover changes in post-socialist countries: Some observations from Hungary and Poland. Land Use Policy 2018, 78, 1-18. [CrossRef]

21. Maantay, J.A.; Maroko, A.R.; Herrmann, C. Mapping population distribution in the urban environment: The cadastral-based expert dasymetric system (CEDS). Cartogr. Geogr. Inf. Sci. 2007, 34, 77-102. [CrossRef]

22. Nicolau, R.; Cavaco, C. Automated delimitation of urban areas comprising small-sized towns-Comparison of two methodologies applied to Mainland Portugal. Environ. Plan. B Urban Anal. City Sci. 2018, 45, 180-201. [CrossRef]

23. Kii, M.; Nakamura, K. Development of a suitability model for estimation of global urban land cover. Transp. Res. Procedia 2017, 25, 3161-3173. [CrossRef] 
24. Milego, R. Urban Morphological Zones Version F1v0-Definition and Procedural Steps. European Environment Agency-European Topic Centre Land Use and Spatial Information. 2007. Available online: http:/ / www.eea.europa.eu/data-and-maps/data/urban-morphological-zones-2000-umz2000f1v0\#tab-methodology (accessed on 15 July 2018).

25. European Environment Agency. Urban Morphological Zones 2006. 2014. Available online: https://www. eea.europa.eu/data-and-maps/data/urban-morphological-zones-2006-1 (accessed on 15 July 2018).

26. European Environment Agency. Urban Sprawl in Europe-The Ignored Challenge. EEA Report-No.10/2006. Available online: http:/ / www.eea.europa.eu/publications/eea_report_2006_10/eea_report_10_2006.pdf (accessed on 2 November 2018).

27. Gisbert, F.J.G.; Martí, I.C.; Gielen, E. Clustering cities through urban metrics analysis. J. Urban Des. 2017, 22, 689-708. [CrossRef]

28. Altieri, L.; Cocchi, D.; Pezzi, G.; Scott, E.M.; Ventrucci, M. Urban sprawl scatterplots for Urban Morphological Zones data. Ecol. Indic. 2014, 36, 315-323. [CrossRef]

29. Wardrop, N.A.; Jochem, W.C.; Bird, T.J.; Chamberlain, H.R.; Clarke, D.; Kerr, D.; Bengtsson, L.; Juran, S.; Seaman, V.; Tatem, A.J. Spatially disaggregated population estimates in the absence of national population and housing census data. PNAS 2018, 115, 3529-3537. Available online: https: / www.eea.europa.eu/airs / 2017 (accessed on 2 November 2018). [CrossRef] [PubMed]

30. Mennis, J.; Hultgren, T. Intelligent dasymetric mapping and its application to areal interpolation. Cartogr. Geogr. Inf. Sci. 2006, 33, 179-194. [CrossRef]

31. Silva, F.B.; Gallego, J.; Lavalle, C. A high-resolution population grid map for Europe. J. Maps 2013, 9, 16-28. [CrossRef]

32. Freire, S.; MacManus, K.; Pesaresi, M.; Doxsey-Whitfield, E.; Mills, J. Development of new open and free multi-temporal global population grids at $250 \mathrm{~m}$ resolution. In Proceedings of the 19th AGILE Conference on Geographic Information Science, Helsinki, Finland, 14-17 June 2016.

33. Gallego, F.J. A population density grid of the European Union. Popul. Environ. 2010, 31, 460-473. [CrossRef]

34. UN-Habitat. Urban Indicators Programme Guidelines; UN-Habitat: Nairobi, Kenya, 2009.

35. Willmott, C.J.; Matsuura, K. Advantages of the mean absolute error (MAE) over the root mean square error (RMSE) in assessing average model performance. Clim. Res. 2005, 30, 79-82. [CrossRef]

36. Silva, F.B.; Poelman, H.; Martens, V.; Lavalle, C. Population Estimation for the Urban Atlas Polygons; EUR 26437; Publications Office of the European Union: Luxembourg, 2013; Available online: http:/ / publications.jrc.ec.europa.eu/repository/bitstream/111111111/30408/1/qms_h08_intesa_ deliverable_2_2_eur_26437.pdf (accessed on 2 November 2018).

37. European Commission. New EU SDG Indicator List Established. 2018. Available online: https:/ / ec.europa. eu/eurostat/web/products-eurostat-news/- /WDN-20170707-1 (accessed on 21 November 2018). 